\title{
Simple and Validated Method for Estimation of Amlodipine by LC-MS (ESI) Using Healthy Indian Human Volunteers: and Evaluation of Pharmacokinetic Parameters
}

\author{
Moses Prince Francis*, Selvadurai Muralidharan, Sekar Rajan, Nagarajan and Bhojraj Suresh \\ Department of Pharmaceutical Analysis, J.S.S.College of Pharmacy, Rocklands Ooty, Tamilnadu, India
}

\begin{abstract}
A simple and validated liquid chromatographic-mass spectrometric method (LC-MS) for amlodipine in human plasma was quantified using LC-MS (ESI). Chromatography was performed on a $\mathrm{C}_{18}$ analytical column, the mobile phase used was Acetonitrile-10mM Ammonium acetate in the ratio of $90: 10 \% \mathrm{v} / \mathrm{v}$ and the retention times were 0.829 and $1.281 \mathrm{~min}$ for azithromycin (Internal standard) and amlodipine respectively. The ionization was optimized using ESI (+) and enhanced selectivity was achieved. The method is validated as per FDA guidelines. The analyte was shown to be stable over the timescale of the whole procedure. The pharmacokinetic parameters such as peak plasma concentration $\left(C_{\text {max }}\right)$, Time to peak Concentration $\left(t_{\text {max }}\right)$, Area under the plasma concentration-time curve $\left(A U C_{0-t} \& A U C_{0-\infty}\right)$, elimination rate constant $\left(\mathrm{K}_{\text {eil }}\right)$, Elimination half-life $\left(\mathrm{t}_{1 / 2}\right)$ were calculated. Log transferred values were compared by Analysis of Variance (ANOVA) followed by classical $90 \%$ confidence interval for $C_{m a x} A \cup C_{0 . t}$. and $A \cup C_{0-\infty}$ and was found to be within the range. These results indicated that the Test and Reference formulation is bioequivalent.
\end{abstract}

Keywords: Amlodipine; LC-MS (ESI); Validation; Pharmacokinetic parameters; Human plasma

\section{Introduction}

Calcium antagonists are a biochemically heterogeneous group of drugs, all the members of which block the entry of calcium to cells by voltage-operated channels (Reid, 1988). Amlodipine is one of a group of medicines known as calcium channel blockers and is indicated for the treatment of hypertension, the prophylaxis of chronic stable angina pectoris. Amlodipine is a dihydropyridine calcium antagonist (calcium ion antagonist or slow-channel blocker) that inhibits the transmembrane influx of calcium ions into vascular smooth muscle and cardiac muscle. (Abernethy, 1989; Kungys et al., 2003). Amlodipine is a peripheral arterial vasodilator that acts directly on vascular smooth muscle. The mechanism of the antihypertensive action of amlodipine is due to a direct relaxant effect on vascular smooth muscle to cause a reduction in peripheral vascular resistance and reduction in blood pressure (Norvasc 2008). Different methods for the determination of amlodipine in biological fluids, such as gas chromatography (GC) (Monkman et al., 1996) or liquid chromatography (LC) (Chitlange et al., 2008a; Shah et al., 2008; Chitlange et al., 2008b) or mass spectrometric analysis (Sarkar et al., 2008; Bohumila et al., 2008; Rohatagi et al., 2008), previously reported methods (Norvasc, 2008; Monkman et al., 1996; Chitlange et al., 2008a; Shah et al., 2008; Chitlange et al., 2008b; Sarkar et al., 2008; Bohumila et al., 2008; Rohatagi et al., 2008) either had long retention time (10-15min) or suffered from low sensitivity and in some cases required large sample injection volumes $(100 \mathrm{~L})$. Hence the main objective of this work was to develop a simple, sensitive rapid and reliable mass spectrometry (LC-MS) method for the quantification of Amlodipine in human plasma. Only limited methods have been reported in the HPLC and GC. The objective of the work was to develop and validate LC-MS method for quantification of Human Plasma. The method shows more sensitive limit of detection and Limit of Quantification is very less to the previous reported methods.

\section{Materials and Methods}

\section{Chemicals and reagents}

Amlodipine and Azithromycin (IS) working standards were used.
HPLC grade Acetronitrile and methanol were manufactured by Qualigens Fine Chemicals, Formic acid AR grade manufactured by S.D. Fine chemicals, Water HPLC grade from Milli-Q RO system was used throughout the analysis.

\section{Chromatography}

The liquid chromatographic system consisting of Shimadzu series LC 10 AD- VP solvent delivery system (pump), CTO $10 \mathrm{VP}$ column oven, SIL 10 AD-VP auto-injector (Shimadzu, Japan) were used for the separation. The detector used was SPD M-10AVP photo diode array detector, DGU 14AM degasser was used. The LC-MS system (ESI) with a quadropole was used for quantitative determination of Amlodipine in human plasma. Data acquisition was performed with LC-MS solution data station software.

\section{LC condition}

Chromatographic separation was achieved on a Princeton SPHER C18 column, $100 \mathrm{~mm} \times 4.6 \mathrm{~mm}$, particle size $5 \mu \mathrm{m}$. Mobile phase used for separation of the analytes was Acetonitrile: $10 \mathrm{mM}$ Ammonium acetate $(90: 10, \mathrm{v} / \mathrm{v})$. The flow rate was set at $1 \mathrm{ml} / \mathrm{min}$. The injection volume was $10 \mu \mathrm{l}$. The Oven was maintained at ambient temperature $\left(30^{\circ} \mathrm{C}\right)$.

\section{MS condition}

Electrospray ionization (ESI) with SIM mode was used to acquire the mass spectra of the compounds. Ions were measured in positive

*Corresponding authors: Moses Prince Francis, Department of Pharmaceutical Analysis, J.S.S.College of Pharmacy, Rocklands Ooty, Tamilnadu, India, E-mail: princefrancis4@rediffmail.com

Received April 17, 2010; Accepted June 26, 2010; Published June 26, 2010

Citation: Moses PF, Muralidharan S, Rajan S, Nagarajan, Suresh B (2010) Simple and Validated Method for Estimation of Amlodipine by LC-MS (ESI) Using Healthy Indian Human Volunteers: and Evaluation of Pharmacokinetic Parameters. J Bioanal Biomed 2: 069-074. doi:10.4172/1948-593X.1000025

Copyright: ( 2010 Moses PF, et al. This is an open-access article distributed under the terms of the Creative Commons Attribution License, which permits unrestricted use, distribution, and reproduction in any medium, provided the original author and source are credited. 
Citation: Moses PF, Muralidharan S, Rajan S, Nagarajan, Suresh B (2010) Simple and Validated Method for Estimation of Amlodipine by LC-MS (ESI) Using Healthy Indian Human Volunteers: and Evaluation of Pharmacokinetic Parameters. J Bioanal Biomed 2: 069-074. doi:10.4172/1948593X.1000025

ionization mode. The tuning parameters were optimized by injecting standard solutions of both Amlodipine and Azithromycin. The turbo ion spray source temperature was set at $37.5^{\circ} \mathrm{C}$ and the turbo ion spray voltage was set at $5500 \mathrm{~V}$. The flow rate of nebulizer gas and the drying gas values were set at $2.5 \mathrm{~L}$ and $10 \mathrm{~L}$ per minute, respectively. The probe temperature was set at ambient and the Block temperature and the $\mathrm{CDL}$ temperature were set to $250^{\circ} \mathrm{C}$ and $200^{\circ} \mathrm{C}$ respectively. The detector voltage was $1.3 \mathrm{kv}$.

\section{Validation}

The real goal of validation process is to challenge the method and determine limits of allowed variability for the conditions needed to run the method.

\section{Selectivity}

Selectivity is the ability of an analytical method to differentiate and quantify the analyte in the presence of other components in the sample. For selectivity, analyses of blank samples of the appropriate biological matrix (plasma, urine, or other matrix) should be obtained from at least six sources. Each blank sample should be tested for interference, and selectivity should be ensured at the lower limit of quantification (LLOQ). Potential interfering substances in a biological matrix include endogenous matrix components, metabolites, decomposition products, and in the actual study, concomitant medication and other exogenous xenobiotics. If the method is intended to quantify more than one analyte, each analyte should be tested to ensure that there is no interference.

\section{Accuracy, precision, and recovery}

The accuracy of an analytical method describes the closeness of mean test results obtained by the method to the true value (concentration) of the analyte. Accuracy is determined by replicate analysis of samples containing known amounts of the analyte. Accuracy should be measured using a minimum of five determinations per concentration. A minimum of three concentrations in the range of expected concentrations is recommended. The mean value should be within $15 \%$ of the actual value except at LLOQ, where it should not deviate by more than $20 \%$. The deviation of the mean from the true value serves as the measure of accuracy. The precision of an analytical method describes the closeness of individual measures of an analyte when the procedure is applied repeatedly to multiple aliquots of a single homogeneous volume of biological matrix. Precision should be measured using a minimum of five determinations per concentration. A minimum of three concentrations in the range of expected concentrations is recommended. The precision determined at each concentration level should not exceed $15 \%$ of the coefficient of variation (CV) except for the LLOQ, where it should not exceed $20 \%$ of the CV. Precision is further subdivided into within-run, intrabatch precision or repeatability, which assesses precision during a single analytical run, and between-run, interbatch precision or repeatability, which measures precision with time, and may involve different analysts, equipment, reagents, and laboratories.

The recovery of an analyte in an assay is the detector response obtained from an amount of the analyte added to and extracted from the biological matrix, compared to the detector response obtained for the true concentration of the pure authentic standard. Recovery pertains to the extraction efficiency of an analytical method within the limits of variability. Recovery of the analyte need not be $100 \%$, but the extent of recovery of an analyte and of the internal standard should be consistent, precise, and reproducible. Recovery experiments should be performed by comparing the analytical results for extracted samples at three concentrations (low, medium, and high) with unextracted standards that represent $100 \%$ recovery.

\section{Calibration/standard curve}

A calibration (standard) curve is the relationship between instrument response and known concentrations of the analyte. A calibration curve should be generated for each analyte in the sample. A sufficient number of standards should be used to adequately define the relationship between concentration and response. A calibration curve should be prepared in the same biological matrix as the samples in the intended study by spiking the matrix with known concentrations of the analyte. The number of standards used in constructing a calibration curve will be a function of the anticipated range of analytical values and the nature of the analyte/response relationship. Concentrations of standards should be chosen on the basis of the concentration range expected in a particular study. A calibration curve should consist of a blank sample (matrix sample processed without internal standard), a zero sample (matrix sample processed with internal standard), and six to eight non-zero samples covering the expected range, including LLOQ.

\section{Lower limit of quantification (LLOQ)}

The lowest standard on the calibration curve should be accepted as the limit of quantification if the following conditions are met: The analyte response at the LLOQ should be at least 5 times the response compared to blank response. Analyte peak (response) should be identifiable, discrete, and reproducible with a precision.

\section{Calibration curve/standard curve/concentration-response}

The simplest model that adequately describes the concentrationresponse relationship should be used. Selection of weighting and use of a complex regression equation should be justified. The following conditions should be met in developing a calibration curve. At least four out of six on-zero standards should meet the above criteria, including the LLOQ and the calibration standard at the highest concentration. Excluding the standards should not change the model used.

\section{Stability}

Drug stability in a biological fluid is a function of the storage conditions, the chemical properties of the drug, the matrix, and the container system. The stability of an analyte in a particular matrix and container system is relevant only to that matrix and container system and should not be extrapolated to other matrices and container systems. Stability procedures should evaluate the stability of the analytes during sample collection and handling, after long-term (frozen at the 7 intended storage temperature) and short-term (bench top, room temperature) storage, and after going through freeze and thaw cycles and the analytical process. Conditions used in stability experiments should reflect situations likely to be encountered during actual sample handling and analysis. The procedure should also include an evaluation of analyte stability in stock solution. All stability determinations should use a set of samples prepared from a freshly made stock solution of the analyte in the appropriate analyte-free, interference-free biological matrix. Stock solutions of the analyte for stability evaluation should be prepared in an appropriate solvent at known concentrations.

\section{Freeze and thaw stability}

Analyte stability should be determined after three freeze and thaw cycles. At least three aliquots at each of the low and high 
concentrations should be stored at the intended storage temperature for 24 hours and thawed unassisted at room temperature. When completely thawed, the samples should be refrozen for 12 to 24 hours under the same conditions. The freeze-thaw cycle should be repeated two more times, then analyzed on the third cycle. If an analyte is unstable at the intended storage temperature, the stability sample should be frozen at $-700^{\circ} \mathrm{C}$ during the three freeze and thaw cycles.

\section{Short-term temperature stability}

Three aliquots of each of the low and high concentrations should be thawed at room temperature and kept at this temperature from 4 to 24 hours (based on the expected duration that samples will be maintained at room temperature in the intended study) and analyzed.

\section{Long-term stability}

The storage time in a long-term stability evaluation should exceed the time between the date of first sample collection and the date of last sample analysis. Long-term stability should be determined by storing at least three aliquots of each of the low and high concentrations under the same conditions as the study samples. The volume of samples should be sufficient for analysis on three separate occasions. The concentrations of all the stability samples should be compared to the mean of back-calculated values for the standards at the appropriate concentrations from the first day of long-term stability testing.

\section{Stock solution stability}

The stability of stock solutions of drug and the internal standard should be evaluated at room temperature for at least 6 hours. If the stock solutions are refrigerated or frozen 8 for the relevant period, the stability should be documented. After completion of the desired storage time, the stability should be tested by comparing the instrument response with that of freshly prepared solutions.

\section{Results and Discussion}

\section{LC conditions}

Chromatographic separation was achieved on a Princeton SPHER C18 column, $100 \mathrm{~mm} \times 4.6 \mathrm{~mm}$, particle size $5 \mu \mathrm{m}$. Mobile phase used for separation of the analytes was Acetonitrile: $10 \mathrm{mM}$ Ammonium acetate $(90: 10, \mathrm{v} / \mathrm{v})$. The flow rate was set at $1 \mathrm{ml} / \mathrm{min}$. The injection volume was $10 \mu \mathrm{l}$. The Oven was maintained at ambient temperature $\left(30^{\circ} \mathrm{C}\right)$.

\section{MS conditions}

Electrospray ionization (ESI) with SIM mode was used to acquire the mass spectra of the compounds. Ions were measured in positive

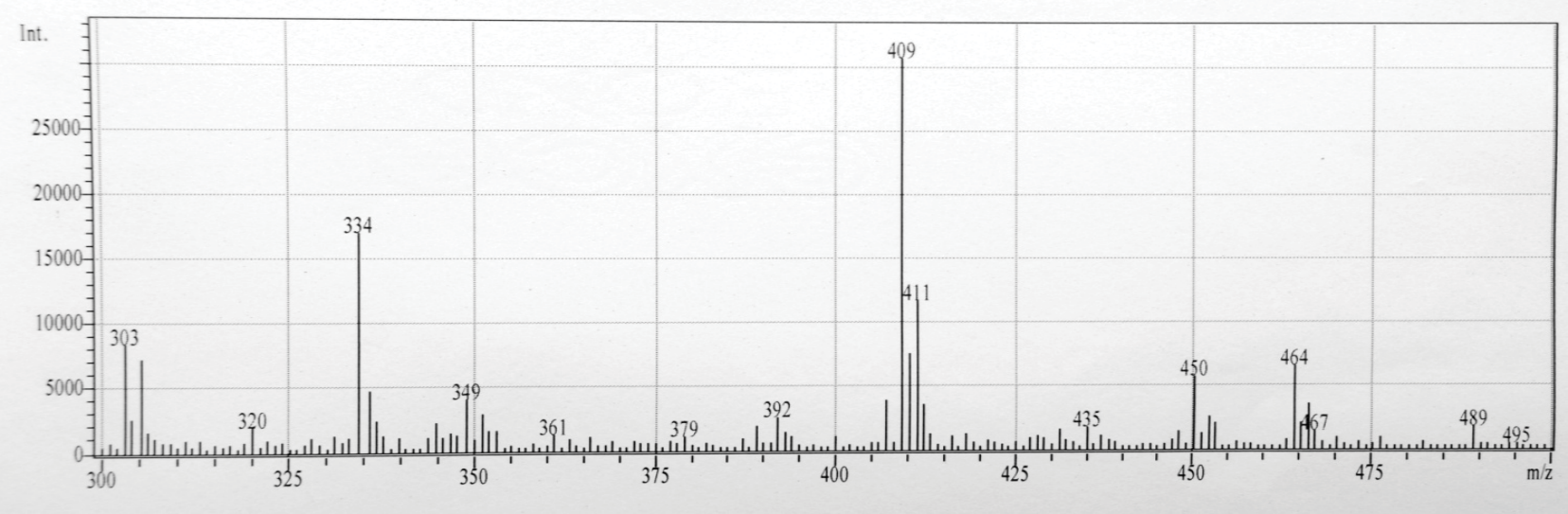

Figure 1: Mass spectrum of amlodipine.

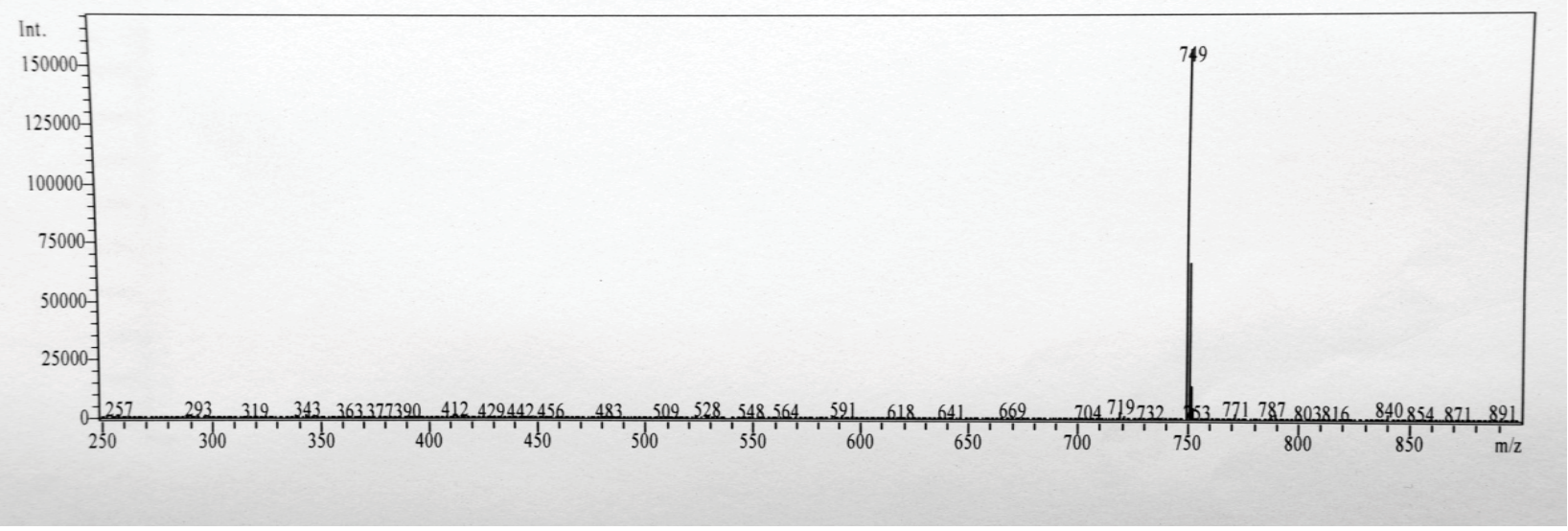

Figure 2: Mass spectrum of internal standard. 
Citation: Moses PF, Muralidharan S, Rajan S, Nagarajan, Suresh B (2010) Simple and Validated Method for Estimation of Amlodipine by LC-MS (ESI) Using Healthy Indian Human Volunteers: and Evaluation of Pharmacokinetic Parameters. J Bioanal Biomed 2: 069-074. doi:10.4172/1948593X.1000025

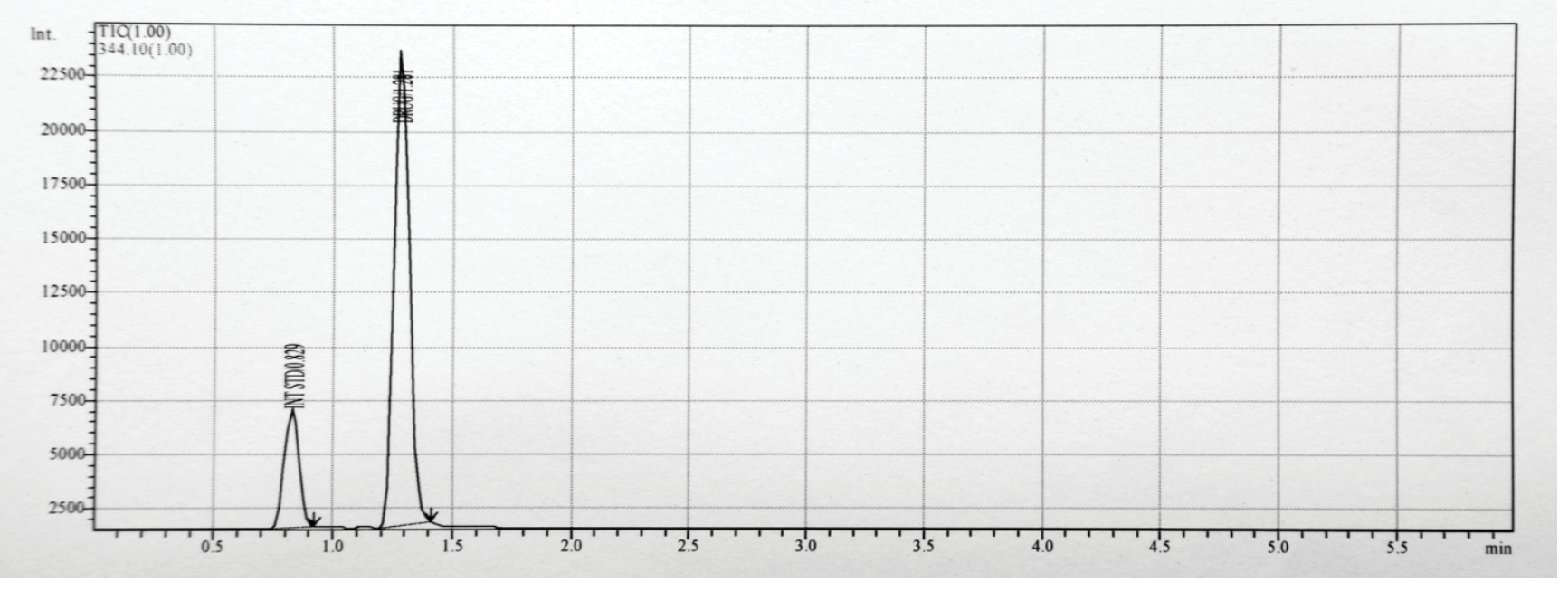

Figure 3: Typical standard chromatogram of amlodipine and internal standard.

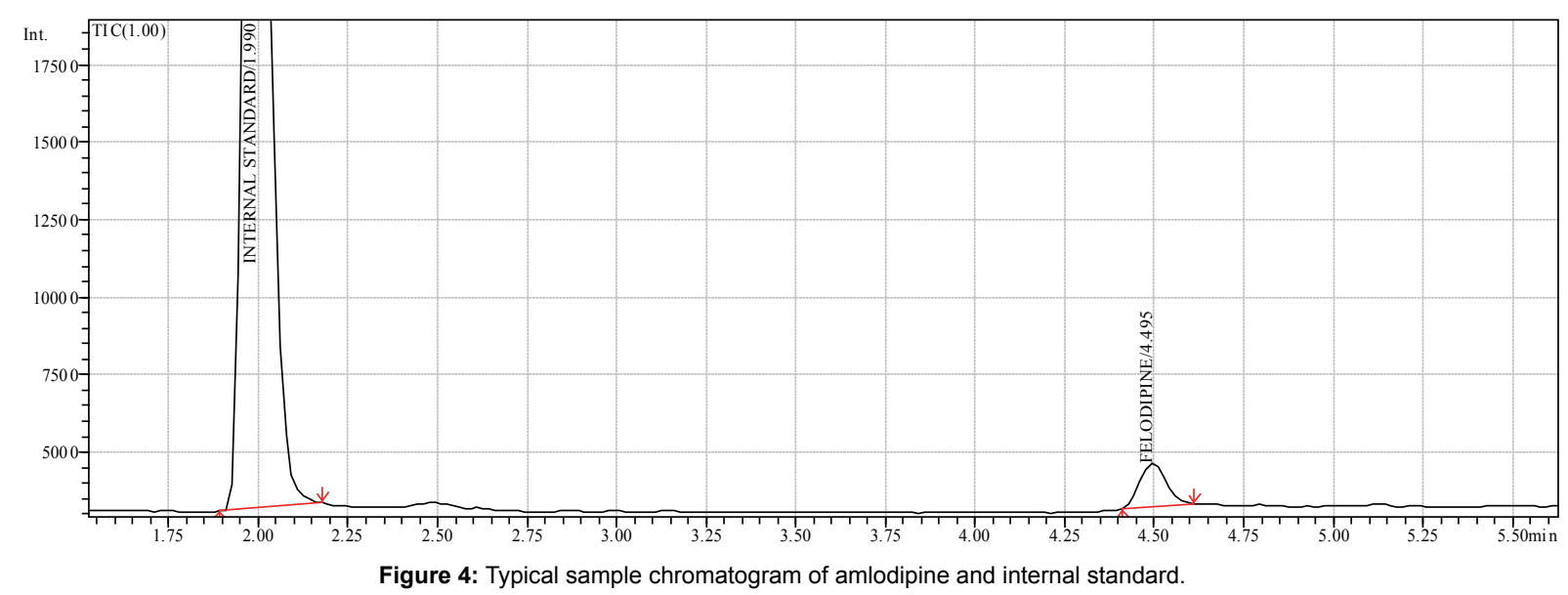

ionization mode. The tuning parameters were optimized by injecting standard solutions of both Amlodipine and Azithromycin. The turbo ion spray source temperature was set at $37.5^{\circ} \mathrm{C}$ and the turbo ion spray voltage was set at $5500 \mathrm{~V}$. The flow rate of nebulizer gas and the drying gas values were set at 2.5 Land $10 \mathrm{~L}$ per minute, respectively. The probe temperature was set at ambient and the Block temperature and the CDL temperature were set to $250^{\circ} \mathrm{C}$ and $200^{\circ} \mathrm{C}$ respectively. The detector voltage was $1.3 \mathrm{kv}$.With the optimised condition, blank plasma sample, standard and sample solutions were injected and the chromatograms were recorded. The optimised condition used for estimation provided a well defined separation between the drug, internal standard and endogenous components. The blank plasma samples showed no interference at retention time of the drugs and their internal standards. (Figure1-4).

\section{Validation of the developed methods}

This section deals with the discussions of the results obtained. The accuracy of the optimised methods was determined by relative and absolute recovery experiments. The percentage recovery values for Amlodipine were ranged from 97.33 to $98.31 \%$ respectively. Their relative recovery values ranged from 98.74 to $99.06 \%$. The coefficient of variation (\%) of these values was less than $2.35 \%$. It is therefore, derived that the developed methods are accurate and reliable (Table $1)$.

The optimized methods for the estimation of the drugs were found to be precise. This was evident from the coefficient of variation values, which were less than $6 \%$ at all concentrations (Table 2).

The six blank plasma samples obtained from six different volunteers were analysed and the chromatograms were recorded. Endogenous interferences were not detected at the retention time of selected drugs and internal standard. The peak purity test method using PDA detector was employed for selectivity studies. The PDA spectrum, first derivative spectrum and peak purity and peak profile curves were recorded and compared. Some additional peaks were also observed in the sample chromatograms. These peaks, however, did not interfere with the drugs and internal standards peaks. These observations show that the developed assay method is specific and selective.

It was observed that the optimised methods were linear within a specific concentration range for individual drugs. The calibration curves were plotted between response factor and concentration of 


\begin{tabular}{|c|c|c|c|c|c|}
\hline Level & $\begin{array}{l}\text { Concentration of } \\
\text { drug added } \mathrm{ng} / \mathrm{ml}\end{array}$ & $\begin{array}{l}\text { Amount of drug } \\
\text { recovered }(\mathrm{ng} / \mathrm{ml}) \text { in } \\
\text { plasma sample }\end{array}$ & Recovery (\%) & $\begin{array}{l}\text { Amount of Drug recovered } \\
(\%) \text { in Mobile phase }\end{array}$ & Relative Recovery (\%) \\
\hline Level-I & 200.00 & $196.08 \pm 0.39$ & $\begin{aligned} \text { Mean }: & 98.31 \\
\mathrm{CV} & : 2.35 \\
\mathrm{~N} & : 6\end{aligned}$ & 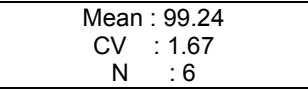 & 99.06 \\
\hline Level-II & 500.00 & $498.67 \pm 1.22$ & $\begin{array}{c}\text { Mean }: 97.65 \\
\mathrm{CV}: 0.72 \\
\mathrm{~N}: 6\end{array}$ & $\begin{array}{c:c}\text { Mean }: & 98.35 \\
\mathrm{CV} & : 1.92 \\
\mathrm{~N} & : 6\end{array}$ & 99.28 \\
\hline Level-III & 1500.00 & $1495.26 \pm 2.05$ & $\begin{array}{c}\text { Mean }: 97.33 \\
C V: 1.38 \\
N: 6\end{array}$ & $\begin{aligned} \text { Mean }: & 98.57 \\
\mathrm{CV} & : 2.41 \\
\mathrm{~N} & : 6\end{aligned}$ & 98.74 \\
\hline
\end{tabular}

Table 1: Recovery studies.

\begin{tabular}{|c|c|c|c|}
\hline \multicolumn{4}{|c|}{ Nominal Concentration (ng/mL) } \\
\hline S.N & LQC & MQC & $\mathrm{HQC}$ \\
\hline & 200.00 & 500.00 & 1500.00 \\
\hline 1 & 192.06 & 472.36 & 1476.32 \\
\hline 2 & 187.19 & 451.88 & 1458.99 \\
\hline 3 & 202.56 & 442.63 & 1493.57 \\
\hline 4 & 192.37 & 484.57 & 1501.88 \\
\hline 5 & 183.47 & 469.44 & 1497.21 \\
\hline Mean & 191.530 & 464.176 & 1485.594 \\
\hline S.D (+/-) & 6.5965 & 16.7781 & 17.7311 \\
\hline C.V. $(\%)$ & 3.44 & 3.61 & 1.19 \\
\hline$\%$ Nominal & 95.77 & 92.84 & 99.04 \\
\hline $\mathrm{n}$ & 5 & 5 & 5 \\
\hline \multicolumn{4}{|c|}{ Nominal Concentration $(\mathrm{ng} / \mathrm{mL})$} \\
\hline S.N & LQC & MQC & $\mathrm{HQC}$ \\
\hline & 200.00 & 500.00 & 1500.00 \\
\hline 1 & 164.32 & 431.62 & 1412.92 \\
\hline 2 & 169.99 & 425.29 & 1462.77 \\
\hline 3 & 175.83 & 434.55 & 1483.69 \\
\hline 4 & 181.04 & 446.23 & 1431.85 \\
\hline 5 & 154.98 & 471.48 & 1457.05 \\
\hline Mean & 169.232 & 441.834 & 1449.656 \\
\hline S.D (+/-) & 10.1339 & 18.2298 & 27.6204 \\
\hline C.V. (\%) & 5.99 & 4.13 & 1.91 \\
\hline$\%$ Nominal & 84.62 & 88.37 & 96.64 \\
\hline $\mathrm{n}$ & 5 & 5 & 5 \\
\hline \multicolumn{4}{|c|}{ Nominal Concentration $(\mathrm{ng} / \mathrm{mL})$} \\
\hline S.N & LQC & MQC & HQC \\
\hline & 200.00 & 500.00 & 1500.00 \\
\hline 1 & 168.29 & 489.32 & 1402.64 \\
\hline 2 & 168.94 & 491.15 & 1429.31 \\
\hline 3 & 175.02 & 431.62 & 1467.21 \\
\hline 4 & 183.46 & 487.55 & 1488.27 \\
\hline 5 & 192.11 & 461.87 & 1478.49 \\
\hline Mean & 177.564 & 472.302 & 1453.184 \\
\hline S.D (+/-) & 10.1637 & 25.6964 & 36.0306 \\
\hline C.V. (\%) & 5.72 & 5.44 & 2.48 \\
\hline$\%$ Nominal & 88.78 & 94.46 & 96.88 \\
\hline 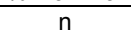 & 5 & 5 & 5 \\
\hline
\end{tabular}

Table 2: Precision Studies ( $\mathrm{ng} / \mathrm{ml}$ ).

\begin{tabular}{|c|c|c|}
\hline $\begin{array}{c}\text { Drug } \\
\text { Concentration (ng/ml) }\end{array}$ & $\begin{array}{c}\text { Internal Standard } \\
\text { Concentration }(\boldsymbol{\mu g} / \mathbf{m l})\end{array}$ & $\begin{array}{c}\text { Response } \\
\text { Factor (RSD) }\end{array}$ \\
\hline 50.0 & 100.0 & 0.005 \\
\hline 100.00 & 100.0 & 0.008 \\
\hline 200.00 & 100.0 & 0.014 \\
\hline 300.00 & 100.0 & 0.021 \\
\hline 400.00 & 100.0 & 0.030 \\
\hline 500.00 & 100.0 & 0.038 \\
\hline 1000.00 & 100.0 & 0.077 \\
\hline 1500.00 & 100.0 & 0.110 \\
\hline
\end{tabular}

Table 3: Linearity and Range.

the standard solutions (Table 3). The linearity range for Amlodipine was found to be, 50.00, 100.00, 200.00, 300.00, 400.00, 500.00, 1000.00 and $1500.00 \mathrm{ng} / \mathrm{ml}$ respectively The calibration curves were constructed on six different days over a period of two weeks to determine the variability of the slopes and intercepts. The results indicated that no significant interday variability of slopes and intercepts over the optimised concentration range.

\begin{tabular}{|c|c|c|c|}
\hline \multicolumn{4}{|c|}{ Nominal Concentration $(\mathrm{ng} / \mathrm{mL})$} \\
\hline Freeze and Thaw & LQC & MQC & HQC \\
\hline & 200.00 & 500.00 & 1500.00 \\
\hline Cycle 1 & 174.36 & 437.06 & 1423.11 \\
\hline Cycle 2 & 177.29 & 426.16 & 1452.89 \\
\hline Cycle 3 & 185.67 & 451.98 & 1478.14 \\
\hline Mean & 179.107 & 438.400 & 1451.380 \\
\hline S.D (+/-) & 5.8698 & 12.9621 & 27.5461 \\
\hline C.V. $(\%)$ & 3.28 & 2.96 & 1.90 \\
\hline$\%$ Nominal & 89.55 & 87.68 & 96.76 \\
\hline $\mathrm{n}$ & 3 & 3 & 3 \\
\hline \multicolumn{4}{|c|}{ Nominal Concentration $(\mathrm{ng} / \mathrm{mL})$} \\
\hline Short Term Plasma at & LQC & MQC & $\mathrm{HQC}$ \\
\hline Room Temperature & 200.00 & 500.00 & 1500.00 \\
\hline After $1 \mathrm{hr}$ & 192.45 & 491.05 & 1428.32 \\
\hline After $2 \mathrm{hr}$ & 196.37 & 482.67 & 1496.47 \\
\hline After $3 \mathrm{hr}$ & 186.48 & 478.55 & 1476.13 \\
\hline Mean & 191.767 & 484.090 & 1466.973 \\
\hline S.D $(+/-)$ & 4.9803 & 6.3698 & 34.9856 \\
\hline C.V. (\%) & 2.60 & 1.32 & 2.38 \\
\hline$\%$ Nominal & 95.88 & 96.82 & 97.80 \\
\hline $\mathrm{n}$ & 3 & 3 & 3 \\
\hline \multicolumn{4}{|c|}{ Nominal Concentration $(\mathrm{ng} / \mathrm{mL})$} \\
\hline Long Term Plasma & LQC & MQC & $\mathrm{HQC}$ \\
\hline Sample at $70^{\circ}$ & 200.00 & 500.00 & 1500.00 \\
\hline After 1 week & 153.21 & 434.16 & 1431.67 \\
\hline After 2week & 134.46 & 426.59 & 1457.92 \\
\hline After 4 week & 142.92 & 441.25 & 1423.75 \\
\hline Mean & 143.530 & 434.000 & 1437.780 \\
\hline S.D (+/-) & 9.3899 & 7.3313 & 17.8856 \\
\hline C.V. (\%) & 6.54 & 1.69 & 1.24 \\
\hline$\%$ Nominal & 71.77 & 86.80 & 95.85 \\
\hline $\mathrm{n}$ & 3 & 3 & 3 \\
\hline \multicolumn{4}{|c|}{ Nominal Concentration ( $\mathrm{ng} / \mathrm{mL}$ ) } \\
\hline Standard Sock solutions & LQC & MQC & $\mathrm{HQC}$ \\
\hline & 200.00 & 500.00 & 1500.00 \\
\hline After $3 \mathrm{hr}$ & 205.63 & 489.27 & 1489.60 \\
\hline After $6 \mathrm{hr}$ & 198.09 & 495.48 & 1502.33 \\
\hline After 4 Week & 199.22 & 499.11 & 1493.07 \\
\hline Mean & 200.980 & 494.620 & 1495.000 \\
\hline S.D (+/-) & 4.0665 & 4.9761 & 6.5808 \\
\hline C.V. (\%) & 2.02 & 1.01 & 0.44 \\
\hline$\%$ Nominal & 100.49 & 98.92 & 99.67 \\
\hline $\mathrm{n}$ & 3 & 3 & 3 \\
\hline
\end{tabular}

Table 4: stability of drug in plasma during storage and sample handling.

The stability of the drug spiked human plasma samples at three levels were studied for three freeze thaw cycles. The mean concentrations of the stability samples were compared to the theoretical concentrations. Similarly, short term (3h), long term (4 weeks) and standard solution stability were evaluated. The stability of the internal standards was also performed. The results showed that the selected drugs were stable in plasma for about one month when stored at frozen state (Table 4).

The limit of detection (LOD) value was found to be $10.0 \mathrm{ng} / \mathrm{ml}$ for Amlodipine and their limit of quantification (LOQ) value was $25.0 \mathrm{ng} / \mathrm{ml}$. This observation showed that the developed methods have adequate sensitivity (Table 5). These values, however, may 
Citation: Moses PF, Muralidharan S, Rajan S, Nagarajan, Suresh B (2010) Simple and Validated Method for Estimation of Amlodipine by LC-MS (ESI) Using Healthy Indian Human Volunteers: and Evaluation of Pharmacokinetic Parameters. J Bioanal Biomed 2: 069-074. doi:10.4172/1948593X.1000025

\begin{tabular}{|c|c|c|c|}
\hline S.No & Parameters & INT STD & DRUG \\
\hline 1 & Theoretical Plate & 6345 & 4689 \\
\hline 2 & Resolution factor & \multicolumn{2}{|c|}{5.48} \\
\hline 3 & Asymmetric factor & 0.64 & 1.52 \\
\hline 4 & $\mathrm{LOD}(\mathrm{ng} / \mathrm{ml})$ & 0.250 & 0.100 \\
\hline 5 & $\mathrm{LOQ}(\mathrm{ng} / \mathrm{ml})$ & 1.00 & 0.250 \\
\hline
\end{tabular}

Table 5: System suitability studies.

be affected by the separation conditions (e.g., column, reagents, and instrumentation and data systems), instrumental changes (e.g., pumping systems and detectors) and use of non HPLC grade solvents and may result in changes in signal to noise ratios.

The ruggedness and robustness of the methods were studied by changing the experimental conditions. No significant changes in the chromatographic parameters were observed when changing the experimental conditions (operators, instruments, source of reagents and column of similar type) and optimised conditions $(\mathrm{pH}$, mobile phase ratio and flow rate).

System suitability parameters such as column efficiency (theoretical plates), resolution factor and peak asymmetry factor of the optimised methods were found satisfactory (Table 5). In conclusion, the developed method for the estimation of Amlodipine in plasma is accurate, precise, selective and linear and is therefore, can be employed for a comparative bioavailability study to evaluate its applicability.

\section{Estimation of amlodipine by HPLC method}

Estimation of plasma samples from the volunteers was carried out using the optimized chromatographic conditions. The standard and sample solutions were injected and chromatograms were recorded. The calibration curves were constructed routinely for spiked plasma containing Amlodipine and internal standard during process of prestudy validation and in-study validation. The mobile phase used for the estimation provided a well defined separation between the drug, internal standard and endogenous components. The zero hour (predose) samples of all subjects showed no interference at the retention time of both the Amlodipine and internal standard.

The response factor of the standard and sample solutions was calculated. The concentrations of Amlodipine present in plasma samples were calculated.

\section{Conclusion}

A simple and validated liquid chromatographic-mass spectrometric method (LC-MS) for amlodipine in human plasma was quantified in human plasma is described. The method was validated and was found to meet all of the requirements of pharmacokinetic and/or bioavailability investigations.

\section{References}

1. Abernethy DR (1989) The pharmacokinetic profile of amlodipine. Am Heart $J$ 118: $1100-1103$.

2. Accessed http://www.ich.org/cache/compo/475-272-1.html for the $\mathrm{ICH}$ Harmonized tripartite Guidelines E1-E8.

3. Bohumila S, Risto K, Raimo AK (2008) Characterization of the in vitro metabolic profile of amlodipine in rat using liquid chromatography-mass spectrometry. Eur J Pharm Sci 33: 91-99.

4. Chitlange SS, Kiran Bagri, Sakarkar DM (2008a) Stability Indicating RP- HPLC Method for Simultaneous Estimation of Valsartan and Amlodipine in Capsule Formulation. Asian J Research Chem 1: 15-18.

5. Chitlange SS, Mohammed I, Dinesh MS (2008b) RP-HPLC method for simultaneous estimation of amlodipine and metoprolol in tablet formulation. Asian Journal of Pharmaceutics 2: 232-234.

6. Douglas AS, James HF, Donald MW (1996) Fundamentals of Analytical chemistry, Saunders College Publisher, Philadelphia 7: 1-15.

7. Kungys G, Naujoks H, Wanner C (2003) Pharmacokinetics of amlodipine in hypertensive patients undergoing haemodialysis. Eur J Clin Pharmacol 59: 291-295.

8. Monkman SC, Ellis JS, Cholerton S, Thomason JM, Seymour RA, et al. (1996) Automated gas chromatographic assay for amlodipine in plasma and gingival crevicular fluid. J Chromatogr B Biomed App 9: 360-364.

9. Norvasc (2008) The Internet Drug Index. RxList Inc.

10. Reid JL, Meredith PA, Donnelly R, Elliott HL (1988) Pharmacokinetics of Calcium Antagonists. J Cardiovasc Pharmacol 7: S22-S26.

11. Rohatagi S, Lee J, Shenouda M, Haworth S, Bathala MS, et al. (2008) Pharmacokinetics of Amlodipine and Olmesartan after administration of Amlodipine besylate and Olmesartan medoxomil in separate dosage forms and as a fixed-dose combination. J Clin Pharmacol 48: 1309-1322.

12. Sarkar Ak, Ghosh D, Das A, Selvan PS, Gowda KV, et al. (2008) Simultaneous determination of metoprolol succinate and amlodipine besylate in human plasma by liquid chromatography-tandem mass spectrometry method and its application in bioequivalence study. J of Chromatogr B Analyt Technol Biomed Life Sci 873: 77-85.

13. Shah DA, Bhatt KK, Mehta RS, Baldania SL, Gandhi TR (2008) Stability indicating RP-HPLC estimation of atorvastatin calcium and amlodipine besylate in pharmaceutical formulations. Indian J Pharm Sci 70: 754-60.

14. Snyder LR, Kirkland JJ, Glajch JL (1997) Practical HPLC method development. John Wiley and Sons, Incorporated 2: 1-14. 